\title{
BUT WHERE ARE THE YOUTH? ON THE VALUE OF INTEGRATING YOUTH CULTURE INTO LITERACY THEORY
}

\author{
Elizabeth Birr Moje \\ College of Education \\ University of Michigan
}

"Literacy is at the heart of world development and human rights," writes Federico Mayor in the opening line of his foreword to Literacy: An International Handbook. ${ }^{1}$ Although this quote comes from only one of the texts from which this essay builds, it could actually be the opening line of any of the three books: Literacy as a Moral Imperative, Literacy for the Twenty-First Century, and Literacy: An International Handbook. ${ }^{2}$ The authors of each text state clearly their belief in the power and promise of literacy even while they acknowledge the potential problem of literacy crusades, as Daniel Wagner does in his introduction to The Handbook:

Whether in the efforts of one religious tradition to dominate another or in revolutionary times for one political group to use literacy to break the mold with a past regime, literacy has at times been used or invoked as a way to divide, separate, and rule from a position of power. Literate traditions have also brought diverse ethnic groups together in common pursuits for mutual benefit. Thus, like all human endeavors, literacy often mirrors what is best (and worst) in human society $(L I A, 1-8)$.

Although each of the three texts represents different philosophical perspectives on literacy and different theoretical and research methods for examining literacy, the texts share several basic assumptions. First, each text assumes that prowess with some form of literacy is a necessity for access to material resources, for political power, and for agency in social interaction. Second, each one assumes that literacy is an undeniable human right. Third, each one assumes that although literacy can be used as a tool to oppress or divide groups, literacy can, if taught well, be a tool of empowerment. Finally, each text assumes that the literacy field - which has been dominated by psychological and literary perspectives - has much to learn about if it is to teach literacy well to various groups around the world. It is this alignment in the underlying beliefs about the power of literacy, and the attention of so many authors to so many different groups of people who deserve access to literacy, that makes all three books' lack of attention to the literacy processes, practices, and development of people aged 12-18 years ("youth, young people, or adolescents," depending on one's theoretical orientation) especially startling.

1. Daniel A. Wagner, Richard L. Venezky, and Brian V. Street, eds., Literacy: An International Handbook (Boulder, Colo: Westview Press, 1999). This text will be cited as LIH in the text for all subsequent references.

2. Rebecca Powell, Literacy as a Moral Imperative: Facing the Challenges of a Pluralistic Society (Lanham, Md.: Rowman and Littlefield, 1999) and M. Cecil Smith, ed., Literacy for the Twenty-first Century: Research, Policy, Practices, and the National Adult Literacy Survey (Westport, Conn.: Praeger, 1998). These texts will be cited as $L M I$ and $L T C$ in the text for all subsequent references. 
It is this lack of attention that I highlight and explore in this essay. I argue that the lack of attention in these three literacy texts to youth culture, to the literacy practices of youth, and to literacy teaching and learning in secondary schools is distressing in part because such neglect makes invisible the literacy practices of a large segment of the world's population. In fact, popular assumptions tend to dominate perceptions about and policies that affect young people and their literacies (and other practices). I also argue that literacy theorists, practitioners, and policymakers should correct popular assumptions about youth and their literacies. Moreover, such understandings would teach us a great deal more about literacy across the life span. Careful empirical and theoretical study of the ways youth use and practice literacy to navigate and manipulate popular culture, academic culture, and the world of work could inform literacy and educational practice before and beyond the adolescent years.

Several studies of adolescent literacy and youth culture have made important contributions to the small body of work in adolescent/youth literacy, but these studies are infrequently represented in the pages of these three texts discussed in this essay, despite the fact that the texts address critical issues in literacy theory, research, and practice. More to the point, no chapter in any of the texts is dedicated to the study or theorizing of youth or secondary school literacy. In fact, the texts are almost explicitly not about youth literacy. Literacy for the Twenty-first Century, for example, is solely devoted to adult literacy. The editors of Literacy for the Twentyfirst Century state explicitly that the 79 chapters of the book are intended to "capture both child and adult literacy," with little mention of youth $(L I H, 1)$. And Literacy as a Moral Imperative, dedicated to advancing a particular form of transformative literacy pedagogy, addresses literacy in general terms, gives few details on the practices of the people at which the pedagogy is aimed, and does not examine the ways that youth, in particular, routinely "transform," as well as disrupt, reshape, reproduce, and resist their own social and school worlds, without the aid of critical pedagogues.

The lack of attention given in these three texts to youth literacy reflects a broader pattern, that when literacy policies are made or funding proposals advanced (at least in the United States), youth culture and literacy almost always remain invisible. ${ }^{3}$ This lack of attention to youth literacy, across educational theory, research, practice, and policy venues, points to unstated assumptions among literacy theorists and policymakers alike that little occurs in the literacy development of youth, that little learning about literacy occurs as youth make use of literacy tools to navigate, resist, construct, and reconstruct popular, academic, and work cultures.

3. Elizabeth B. Moje et al., "Reinventing Adolescent Literacy for New Times: A Commentary on Perennial and Millennial Issues in Adolescent Literacy," Joumal of Adolescent and Adult Literacy 43 (2000): 400-11 and Richard T. Vacca, "Foreword," in Reconceptualizing the Literacies in Adolescents' Lives, ed. Donna E. Alvermann et al. (Mahwah, N.J.: Lawrence Erlbaum Associates, 1998), xv-xvi.

ELIZABETH BIRR MOJE is Associate Professor at the University of Michigan, 610 E. University, 1302 SEB, Ann Arbor, MI 48109-1259. Her primary areas of scholarship are youth literacy and youth cultural studies. 
Thus, when considered as a set, these texts reveal dominant assumptions about literacy in the field: Whether professing literacy to be a cognitive process, a social practice, or a political tool, policymakers, researchers, and theorists betray a belief that literacy learning ends in childhood, only to be remediated in adulthood if not learned correctly in the early years. This lack of theory about the potential change in the literacy practices of young people as they venture into secondary schools and into a globalized, complex world, combined with the national and international concern over recent acts of violence among young people worldwide, leads me to write about youth culture and youth literacy in this essay.

I will argue that the lack of attention to youth is not a mere oversight and that it has consequences for how the literacy field thinks about literacy learning and teaching. An analysis of how youth are positioned in educational theory and in popular culture reveals that youth are often dismissed from the literacy education radar screen because it is assumed that their literacies and other practices are confused at best, and troubled or villainous at worst. ${ }^{4}$ Drawing from this analysis, I contend that literacy theorists need to pay more attention to youth and to the youth studies conducted in disciplines outside the literacy education field, in part to support youth in constructing successful and happy adult lives. Furthermore, if literacy theorists turn our attention to youth and study how they learn the increasingly complex literacy practices required in disciplinary discourse communities, how they reinvent literacies for unique contexts, and how they use literacy as a tool to navigate complex technologies and fragmented social worlds, then we might learn more about literacy learning among children and adults.

\section{WHERE ARE THE YOUTH? A SYNOPSIS OF THE BOOKS}

It is hard to imagine what might be said about literacy beyond that which has already been written in the pages of these three diverse texts. The books represent the perspectives of roughly 110 different authors (several chapters in the two edited collections were co-authored), making any neat summation of the three texts virtually impossible. Obviously, each of the three books makes literacy its central theme, but that is where the similarity among books ends (and what counts as literacy in each text is vastly different). In fact, I would be hard-pressed to think of three more different books, differences that play out in tone, style, and format. Almost any perspective on literacy that one might imagine - from autonomous to ideological models, from cognitive to cultural models from banking to critical models - is represented. I begin my synopsis of the books by discussing the books' goals in relation to how each author or set of authors defines literacy.

\section{What Counts as Literacy When Literacy Gets Promoted?}

Literacy: An International Handbook presents the greatest range in terms of the perspectives presented on what literacy is and what it does for people. The range of perspectives result from its nature as a collection of approximately 100 authors who represent, as Daniel Wagner argues in the introductory chapter, the diversity of perspectives that characterize not only the field, but the complex and amorphous

4. Mike A. Males, The Scapegoat Generation (Monroe, Me.: Common Courage Press, 1996). 
nature of the construct itself. The thrust of the Handbook, then, is that literacy is not a single thing, that it cannot be neatly defined, and that the researching and teaching of literacy, consequently, requires multiple and hybrid practices. To achieve this goal, the editors brought together scholars from multiple epistemological, theoretical, and methodological perspectives to examine literacy from many different angles. At times these angles challenge each other. A reader can literally flip from page to page and read different, sometimes contradictory, claims about what counts as literacy, with each claim having dramatic implications for how literacy should be studied. For example, consider just a few of the claims made about literacy across just five chapters:

Literacy in social history can be understood as any kind of written or oral communication employing language to achieve desired social ends $(L I H, 16)$.

Literacy is the ability to read and write $(L I H, 29)$.

Literacy is a social practice $(L I H, 37)$.

Literacy from a cultural-historical perspective [is] not a static thing but in the context of dynamically developing civilization, as a spiritual measure of the individual's cultural standards, and as a prerequisite for involvement in civilized life. The definition of the basic level of literacy, which should be accessible to all, must include the entire complex of knowledge and skills and, no less important, the cultural and moral values that are socially important for the development of the individual and for independent and responsible involvement in public life and work $(L I H, 393-94)$.

Literacy is not an end itself but a means to achieve many ends $(L I H, 410)$.

Literacy is a significant part of the activities of many people who have not been formally taught to read and write and might even regard themselves as illiterate, with reference to a model of standard literacy $(L I H, 421)$.

Despite the argument that literacy is diverse, fluid, hybrid, and multiple, not one chapter in the Handbook addresses the literacies of youth / a particularly hybrid and fluid group) or the impact of youth culture (popular, everyday, or academic) on how youth practice or leam literacy. Chapters move back and forth between examining theoretical and empirical perspectives on child and adult literacy, including instructional perspectives (but none that are situated in secondary school settings). Sections are devoted to studying the relationships between language and literacy and between numeracy and literacy. More than twenty chapters examine literacy policies - not one of which address policies aimed at youth. A comprehensive section is dedicated to literacy campaigns and programs in 16 regions of the world. A final section is devoted to literacy and new technologies. Even in that final section, an area in which young people between the ages of 12 and 20 are, according to some, in their finest and potentially most troubled hour, ${ }^{5}$ no attention is given to how youths navigate,

5. Thomas J. Cottle, Mind Fields: Adolescent Consciousness in a Culture of Distraction (New York: Peter Lang, 2001); Neil Howe and William Strauss, Millennials Rising: The Next Great Generation (New York: Vintage, 2000); and Colin Lankshear and Michele Knobel, "Do We Have Your Attention? New Literacies, Digital Technologies, and the Education of Adolescents," paper presented at the New Literacies and Digital Technologies: A Focus on Adolescent Learners Conference, Athens, Ga., 26 January 2001. 
manipulate, and are dominated by the images and icons of popular culture, media, Internet web pages, chat rooms, and other technologies. And in a chapter on family literacy, Vivian Gadsen points out that family literacy programs focus on providing "literacy instruction and assistance to parents, grandparents, other adult family members, as well as to children" $(L I H, 258)$. While the word "children" in family literacy programs may be intended to focus on anyone who is not technically an adult, the fact that adolescents or youth are not explicitly named as a focus group in such programs reveals the way that adolescent readers and writers are made invisible even in policies that seek to enhance literacy outside of school.

John Guthrie and Jamie Metsala, in their chapter, "Literacy in North America," do refer to young people in grades 4-12, emphasizing the importance of understanding engagement as an aspect of reading comprehension and achievement. They argue that

A highly achieving student, whether at grade four, eight, or twelve, must not only comprehend passages of text but must also (1) integrate information across multiple texts, (2) critically relate paragraph meanings to personal experience, (3) employ knowledge from texts to evaluate science observations or historical documents, and (4) compose complete messages in the form of stories and reports for actual audiences $(L I H, 16)$.

According to Guthrie and Metsala, data provided in the National Assessment of Educational Progress (NAEP) indicate that North American, or at least U.S., youth are struggling to achieve along these dimensions of literate practice. Given that such abilities are required for high literacy achievement among youth and that youth seem to be struggling to acquire these abilities, it seems even more perplexing that so little attention is paid to them in this book.

The goal of Literacy for the Twenty-first Century is to expand on information gained through the National Adult Literacy Survey (NALS) about the power of literacy in adult people's lives. In their introduction, Cecil Smith and Stephen Reder argue that the NALS data provide an "accounting" of specific "literacy skills and practices and the sociocultural and demographic factors that are associated with the skills and practices [of literacy] in the late twentieth century" (LTC, 5). They argue that a single analysis of this complex survey data set cannot adequately show the economic and social consequences of literacy practices in the lives of adults, thus setting the stage for secondary analyses of how literacy practices are shaped by contexts such as workplace, family, and school. Contributors to the volume also examine how differences in gender and learning ability or disability appear to shape literacy practices (showing that literacy is not only powerful, but dependent on other qualities of being) and how voting and health care practices are correlated to literacy habits and proficiencies. These varied analyses combine to present a more comprehensive, although necessarily broad, portrait of how literacy shapes adult life and is reflected in adult life practices.

Unlike the Handbook, this book uses a single definition of literacy. Specifically, the authors work from Jungeblut, Kirsch, Jenkins, and Kolstad's 1993 NALS definition of literacy: "[u]sing printed and written information to function in society, to achieve one's goals, and to develop one's knowledge and potential" (LTC, 4). 
Although Smith argues that the NALS definition of literacy is broader than definitions used in past U.S. censuses, the definition is significantly tighter than definitions offered in the other two volumes. The focus on print and written text circumscribes attention to a particular kind of literacy practice - usually those kinds of practices found in the workplace or in domestic chores - as does its focus on adults alone.

Smith's text can, of course, be forgiven its lack of attention to youth literacies because it is explicitly aimed at analyzing data drawn from a test designed for adults. Nevertheless, developments in youth literacy, particularly around language acquisition and electronic technologies, may have important implications for interpreting the NALS data. The boundary between youth and adulthood is, after all, a rather thin and meandering one. Many young people engage in tasks that are quite "adult" in nature. The children of adults who do not read and write English in the United States, for example, often serve as "language brokers," routinely translating documents, advertisements, and instructions, and at times managing the majority of household written language tasks. ${ }^{6}$ Examining adults' literacy practices out of the context of their everyday lives, then, as one might do in a survey, neglects the support systems available to adults via their adolescent children. Conversely, failing to attend to the literacy practices of people who will soon be adults narrows the contextual field available for understanding why adults perform as they do on the NALS and other adult literacy surveys. What literacy experiences were not made available to these adults in their youth? What literacy practices, skills, and strategies important to adults with different youth experiences and backgrounds are not assessed in surveys such as the NALS?

Unlike Smith's book, Rebecca Powell's Literacy as a Moral Imperative is not an empirical piece, per se. Rather, she uses extant studies to argue for a critical literacy pedagogy in which students learn to use literacy to construct a just and democratic society. Powell writes passionately of her aim to encourage readers to engage in a critical praxis so that "they too might come to an understanding of the reproductive tendencies of education" $(L M I, 5)$. To further this goal, she reviews sociocultural and critical literacy theories and studies to support her claim that literacy is a social, cultural, and, thus, moral act. She then offers some of her own experiences as a university teacher, together with the empirical work of other scholars on child and youth literacy learning, to advance five criteria for constructing a "transformative literacy" for a "participatory democracy." Specifically, she argues that literacy instruction ought to

\footnotetext{
1. Promote freedom of thought through encouraging diverse perspectives and welcoming productive critique;

2. Enhance students' communicative competence by considering social, cultural, and hegemonic dimensions of language use;

3. Be consciously political;
}

6. Robert Jimenez, "Literacy and Identity Development of Latina/o Students," American Educational Research Journal (2001) and Marjorie Faulstitch Orellana, "Mediating Mediation: Immigrant Children as Language Brokers or "Para-Phrasers'"; paper presented at the National Reading Conference, Scottsdale, Ariz., December 2000. 
4. Be taught in ways that make students aware of the power of language for transformation;

5 . Be taught in ways that nurture a culture of compassion and care $(L M I, 65)$.

Powell argues that with critical pedagogy can come a "proper literacy"7 that

challenges us to look beyond our limited cultural assumptions and world views; ...that not only legitimates students' voices but allows them to see that they are part of the continuing human dialogue, and that their lives can make a difference $(L M I, 6)$.

Thus, Powell conceptualizes literacy as a transformative tool and writes eloquently of the need to make this tool accessible to all.

In making this exhortation, Powell does not aim her pedagogical imperatives at any particular age group; indeed, Powell's use of data drawn from the published studies of other scholars suggests that the practices she calls for are applicable across the ages, although her examples are more often drawn from studies involving upperelementary-aged students than from young children, older adolescents, or adults. Given her apparent assumption that this critical, or "proper" literacy pedagogy is not restricted to a particular point in a person's development, one is left with the question of how students - whether children, adolescents, or adults - might achieve the facility with print and the knowledge and information necessary to engage in the critical literacy activities she suggests to support each criterion. Such a question, one could argue, is answered in some of the Handbook chapters the section on "psychological approaches" to literacy addresses specifics of written language acquisition), but such chapters tend to operate from narrower conceptions of what counts as literacy, and use vastly different methods from those used in the studies Powell cites. Readers are left with the question of how people move from the acquisition of written language code in simple texts to interpretation and synthesis of written language in and across increasingly complex texts (such as in science, history, or mathematics texts), to the use of written language as a transformative tool in these areas and in everyday life. The question of how one learns to access and use complex content texts at both the word level, the conceptual level, and the transformative level - a question often posed by secondary and adolescent literacy scholars - is left unaddressed across the three texts. Powell might argue that she is addressing this question by putting forward the five moral imperatives for literacy instruction listed above. But an examination of each of these imperatives, and Powell's arguments for how these imperatives get enacted, reveals that Powell assumes a certain facility with language that several adolescent literacy scholars would argue many young people lack or are in the process of developing during adolescence. $^{8}$

Although Powell assumes basic facility with language, she seems to deny the possibility that young people might already be engaged in a kind of critical analysis of the world and their experiences in it. One wonders whether Powell's pedagogical

7. Colin Lankshear and Moira Lawler, Literacy, Schooling, and Revolution (Philadelphia: Falmer Press, 19871 .

8. Gay Ivey, "A Multicase Study in the Middle School: Complexities among Young Adolescent Readers," Reading Research Quarterly 34, no. 2 (1999): 172-93. 
dicta might be reshaped were she to study how young people (or any people) actually use literacy to make meaning, to disrupt conventions, to resist unwanted practices, and to change their lives outside of school, without the benefit of a formal critical literacy pedagogy. That is, Powell seems to assume that youth cannot engage in critique unless they are taught explicitly to be critical and to be critical in a particular way. A number of youth studies challenge that assumption about youth by illustrating that youth use literacy in myriad of different ways that often appear mainstream, but are coded with resistance and group membership. ${ }^{9}$ Powell, however, does not draw from such studies of youth culture and youth literacy.

Furthermore, although Powell presents moving artifacts of children's and young people's literate engagements from already published studies, her own work revolves around teaching teachers how to teach a "proper" literacy. A number of Powell's borrowed examples are drawn from the writing of youths, but she does not analyze what youth are learning, representing, or navigating as they engage in these writings. Thus, although Powell's book comes closest among the three to addressing questions of what it means for youth to engage in literacy, she focuses on teaching a particular kind of literacy, framed by her principles and criteria. She does not write about who youth are, and why and how they use literacy in and out of school.

THE POWER OF LITERACY

Although each of these texts (especially the Handbook) present a range of perspectives on literacy, all the authors appear to agree that literacy is a powerful thing. However, their specific views on the power of literacy run the gamut as well, with at least five views articulated in and across these texts.

One view is that the power of literacy is wrapped up in the cognitive consequences associated with using literacy. Scholars who make this argument in (and out of) these texts typically argue that literacy produces changes in human consciousness, changes that have implications for the kind of thinking people can do and for the accomplishments they can achieve. ${ }^{10}$ Such a view of the power of literacy - a view that has been challenged over the past twenty years - is most prominently argued in the Handbook's sections on the historical and philosophical roots of literacy and on psychological approaches to literacy.

A second view on the relationship between literacy and power is that learning literacy skills allows one to participate more fully in economic and social decisionmaking with, as Federico Mayor states, "infinite possibilities of transmission and therefore of active participation in communication" $(L I H$, xiii-xiv). This view is quite clearly articulated in Literacy for the Twenty-first Century and in the

9. Donna E. Alvermann et al., "Changing Our Understanding of the Critical"; paper presented at the National Reading Conference, Scottsdale, Ariz., December 2001 and Michele Knobel and Colin Lankshear, "Cut, Paste, and Publish: The Production and Consumption of Zines"; paper presented at the New Literacies and Digital Technologies Conference, Athens, Ga.: January 2001.

10. Jack Goody, "The Implications of Literacy," in Wagner, Venezky, and Street, Literacy: An International Handbook, 29.33; Walter Ong, Orality and Literacy: The Technologizing of the Word (New York: Routledge, 1982); and Lev S. Vygotsky, Mind in Society, ed. Michael Cole et al. (Cambridge: Harvard University Press, 1978|. 
Handbook chapters on literacy campaigns in various regions of the world. C.J. Daswani, for example, concludes his assessment of adult literacy campaigns in India with the argument that "Only when a society uses literacy as an essential tool for socioeconomic survival is the individual motivated to acquire the literacy skills necessary for functioning within that society" $(L I H, 438)$.

A third view suggests that gaining access to the literacy skills or practices of the dominant - the "culture of power" to borrow from Lisa Delpit - provides one the skills or practices necessary to compete with those in power, bringing economic or social benefits to the individual, but not necessarily bringing economic or social change to systems of power. ${ }^{11}$ Again, this view is explicitly expressed in Literacy for the Twenty-first Century and the Handbook, which offer the argument that such literacy skills or practices are not necessarily better than other ways of communicating, nor do they lead to particular cognitive consequences, but they are necessary for competing in the existing socioeconomic structure. Such a view is clearly tied to a view of literacy as a tool for economic gain, but in this perspective, the tool is explicitly tied to the culture of power rather than to a cognitive consequence that enables an individual to produce more resources or attain more status in an economic structure.

The previous perspective is tied to a fourth view on the power of literacy as being embedded in culture and context, so that what counts as powerful literacy in one culture or social context may be relatively ineffectual in another. The Handbook authors who contributed to the section on sociological and anthropological approaches to literacy speak from various contexts about the power of literacy as dependent on context and culture, rather than viewing literacy as a cognitive consequence that transfers from one context to another with an individual person's mental functioning $(L I H, 95-101)$. Similarly, Powell subscribes to a culturally rooted view of literacy and power at some level, although her arguments about the moral obligation of educators to expose students to the transformative power of literacy could be read as suggesting that a certain kind of literacy is always powerful, in part because it encompasses the ability to navigate across contexts.

Finally, a fifth view suggests that learning literacy - a particular kind of literacy - allows one to be aware of, critique, and challenge unequal power relations. Literacy as a Moral Imperative best represents this view, with Powell's consistent argument that what students need is a "critical literacy...one that liberates" and a "counterhegemonic language... one that takes sides - toward a more just, equitable, and compassionate world" (LMI, 80). In this perspective on the power of literacy, literacy serves as a tool for critique, rather than a tool for economic or social gain. Here, the tool is used to challenge and change structures of power.

None of these views on the power of literacy is, of course, mutually exclusive in theory; it can certainly be argued that the cultural consequences of literacy are indeed cognitive consequences as well, or that gaining access to the skills valued in the 
culture of power can be useful in disrupting that culture. But the books do not present these multiple views on the power of literacy as intersecting or complexly related; Powell and Smith's books operate from one view of literacy's power, whereas the Handbook presents a pastiche of perspectives on literacy. Smith, for example, treats the power of literacy from an obviously economic perspective:

If our nation is to continue to be a world leader well into the next century, we must find ways to ensure that all of our citizens possess the literacy skills that are needed to function effectively in a complex, highly technological, and information-driven culture (LTC, 11).

Although each of this book's authors writes about literacy's power in relation to different qualities of adult life - from health care to political practice - their analyses remain rooted in a conception of literacy as a tool for individual economic and social life enhancement.

Powell, by contrast, begins with a decidedly political perspective:

I argue in chapter 5 that literacy instruction ought to be consciously political, that literacy ought to be taught in ways that illuminate the hegemonic functions of language and knowledge and that nurture a critical social consciousness, so that students and teachers become cognizant of the ways in which they are both victims of and unwitting corroborators in a system of dominance and control $(L M I, 6)$.

The Handbook, on the other hand, purports to offer a multifaceted perspective on literacy, and does indeed include sections that present different ways of defining literacy and of viewing its consequences. Despite Wagner's opening credo, however, in which he argues that literacy mirrors what is best and worst in society, his book makes little attempt to illustrate how the power of literacy can be oppressive at the same time that it is liberating, that is, literacy can be taught as a tool for accessing a wide range of texts and knowledge, but literacy can also be taught in ways that constrain people's access to texts and knowledge. Nor does the Handbook weave perspectives together in a way that presents a complex image of literacy; instead, it lays out many different views and leaves the reader to sort out how the views might actually all be accurate. There is, in fact, no dialogue across chapters, except as laid out in Wagner's introduction to the text.

Thus, the three books agree that literacy is a powerful thing, whether that thing is defined as a cognitive skill, a cultural practice, or a political tool. But none of the books examines how adolescents or youth learn and use literacy in powerful ways. None of the books examines the cognitive consequences of literacy engagements among adolescents. None of the books examines how adolescents use literacy for economic betterment or as a political tool. And, finally, none of the books discusses how youth culture and popular media cultures that youth engage might shape the kinds of literacy they practice. ${ }^{12}$ We do not see in these books the power of literacy for youth to engage in identity construction and representation, to carve out unique social spaces, or to experiment with new technologies for engaging in written and oral communication. More important, the reader may be left wondering how people move from child as reader and writer to adult as reader and writer. Are the transitions obvious once one learns the basic language codes?

12. Cottle, Mind Fields and Howe and Strauss, Millennials Rising. 
In sum, the books, despite their differences in stance and method, share two especially troubling common - and related - themes: They do not address the literacy practices of youth, and they do not explore the complexity of using and learning literacy in an increasingly complex, globalized, and hybrid world. I argue that these themes are related because to study the literacy practices of youth is to study complexity, globalization, and hybridity. As Jean and John Comaroff argue, "youth tend everywhere to occupy the innovative, uncharted borderlands along which the global meets the local."13 Youths' access to and fascination with information technologies, mass media and popular culture, mass transportation, and multiple disciplines of the secondary school provide them with multiple sources of information, contact with people of backgrounds different from theirs, and diverse texts and experiences. ${ }^{14}$ Youth in a postmodern world can hardly help but construct complex and hybrid identities. Thus, to study youth literacy is to study the complexity of literacy's power. We can examine, through the study of youths using old literacies and inventing new literacies, how all people learn literacy in new situations, use literacy to navigate multiple experiences, and use multiple experiences to construct new literacies. ${ }^{15}$ Further, studying youths' literacy practices allows for an examination of the ways that literacies and identities intersect, the consequences of literacy for a new economy (and vice versa), and the consequences of literacies for a new social order. ${ }^{16}$ Finally, bringing youth studies to bear on literacy theory, research, practice, and policy brings youths' voices to the fray.

\section{On Literacy, Youth, Adolescence, And Youth Culture}

To move toward a more detailed argument about the importance of studying youth culture and youth literacy, a few definitions of terms such as "literacy," "youth," and "adolescence" are in order. Literacy, as illustrated in the springboard texts for this essay, is an ill-defined and at times hotly contested term. Certainly many would agree that literacy at its most basic level refers to the reading and writing of written texts, but many scholars also go beyond that fairly narrow definition to expand what counts as reading and writing, as well as to broaden what counts as text. For my purposes in this essay, I will bring together the myriad definitions of literacy in these texts to define literacy as the ability to produce and interpret permanently encoded, communicative texts. However, to assume that literacy involves only the ability to produce and interpret (write and read) print or other permanently encoded texts is to capture only a part of what is involved in literate practice. In addition to permanent codes, a number of symbol systems, signs, and even "raw" or unintentional movements contribute to making and representing meaning in addition to and

13. Jean Comaroff and John L. Comaroff, "Millennial Capitalism: First Thoughts on a Second Coming," Public Culture 12, no. 2 (2000): 291-343, 308.

14. Allan Luke and John Elkins, "Reinventing Literacy in "New Times," Journal of Adolescent and Adult Literacy 42 \{1998\}: 4-7.

15. Lankshear and Knobel, "Do We Have Your Attention?"

16. James Paul Gee, "Millennials and Bobos, Blue's Clues and Sesame Street: A Story for Our Times"; paper presented at the New Literacies and Digital Technologies Conference, Athens, Ga., 26 January 2001. 
in conjunction with written language, ${ }^{17}$ Without each of these forms of representation, reading and writing would be limited tools, virtually incapable of producing the layered understandings and shifts in thinking that have been attributed to them. Specific to my own research on the literacy practices of gang-connected youth, for example, are the works of art, music, dress codes, make-up, tattoos, body movements, gestures, and hand signs that youths used to identify themselves and to claim power and space in and out of their gang affiliations..$^{18}$ Each of these symbol systems and signs deepened and extended the meanings represented and communicated in the written texts of the youth I studied. In fact, some acts of reading and writing would have very different meanings were it not for the other representational forms that accompany those acts, all points that help to show the value of studying the complex iteracy practices of youth.

Thus, literacy, even when defined as the reading and writing of print, cannot be well understood unless one attends to people's literacy practices - the values, beliefs, and actions that people bring to reading and writing and to the multiple symbol systems and signs with which reading and writing of print are articulated.

Moreover, written and other (such as spoken or performed) texts and the literacy practices that people use to make sense of such texts serve as cultural tools for establishing personhood, ways of knowing, or discourses and identities. ${ }^{19}$ The idea that texts and literacy practices both constitute and are constituted by our "identity kits" is useful for thinking about the import of studying youth literacy, in particular. ${ }^{20}$ If, as some assert, adolescence is a time of "becoming" or at least a time of choice-making and hybridity, then it seems all the more important to study aspects of the kits that are forming and being formed by youths' identities.

Definitions of identity are, of course, highly contested, and become especially complicated when one attempts to examine how particular cultural relations - such as being in a gang, for example - intersect with ethnic, gender, and class relations, and how all of those relations shape uses of literacy and one's identity. If it can be assumed that identity is not a stable, unitary construct and that, instead, any one person can construct many different identities as he or she moves through many different contexts, then it again becomes clear why the field should pay attention to youth. Young people - because of their immersion in many different contexts and spaces of experiences - must navigate multiple practices and experiences that shape how they use literacy and construct identities. In fact, it might be argued that youth must navigate a greater number of different practices than children and adults navigate on a daily basis. The field has much to gain by studying how different literacy practices are learned and what the consequences are for identity development and content learning among youth.

17. Elliott W. Eisner, Cognition and Curriculum Reconsidered, 2 d ed. (New York: Teachers College Press, 19941.

18. Elizabeth B. Moje, "To Be Part of the Story: The Literacy Practices of Crangsta Adolescents." Teachers College Record 102 (2000): 652-90.

19. Brian V. Street, "Cross Cultural Perspectives on Literacy," in Language and Literacy in Sacial Practice, ed. Janet Maybin (Clevedon, England: Open University Press, 1994), 139-50.

20. James Paul Gee, Social Linguistics and Literacies: Ideology in Discourses, 2d ed. (London: Falmer, 1996). 


\section{Who ARE Youth AND Why DON'T We Study TheM?}

How one answers the question "Who are youth?" depends on the theoretical perspective scholars take on the time period popularly called teen years, adolescence, or youth. Broadly speaking, youth and their experiences have been examined from two different stances in the field of education. One stance focuses on adolescence as a stage or period of development, whereas the second stance examines the experiences and behaviors of youth as part of normed sets of practices, behaviors, and beliefs common to people of a certain age or generation, typically referred to as youth culture(s).

Only in recent years have researchers and theorists in the field of literacy and language education turned to either stance as a way of examining the literacy practices of youth. Prior to the late 1980 s, literacy researchers and theorists who studied the literacy learning of youth confined their study to secondary school classrooms and focused their work on the demands made on older literacy learners as they attempted to extract information from content area texts. Thus, adolescent and youth literacy research is a relatively new phenomenon (and the field of secondary school and disciplinary literacy is not much older); however, work in these areas has expanded over the last twenty years to include an important focus on how youth use and learn literacy in multiple spaces and for multiple purposes. This work has drawn largely from psychological, sociological, and anthropological perspectives on adolescence and, to a lesser extent, from cultural studies of youth.

AdOlescence As BIOLOgY: HoRmones, HoRmones, HoRmones. Both popular notions and theoretical perspectives on adolescence assume a link between biology - or physiological changes - and cognitive and affective changes in young people. $\mathrm{C}$. Stanley Hall referred to adolescence as a phase of "storm and stress" resulting from hormonal changes at the onset of puberty. ${ }^{21}$ Whether the hormonal explanation remains rooted in biology (the body is out of control) or is psychologized (body changes lead to mind changes], the popular conception is that the adolescent lives at the whim of these physical, embodied changes. Certainly the importance of examining the impact of hormonal changes on people's behavior and experience should not be dismissed, but the popular assumption that hormones are everything in adolescence leads many parents, teachers, and theorists alike to position youth as nothing more than a "bundle of raging hormones." ${ }^{22}$ By and large, this raging hormone discourse reduces adolescents to people who are out of control, with cognitive and social development backgrounded to physiological development. The raging hormone model fosters an image of the wild, troubled, sweaty, and lustful teen just looking for action, which promotes a fear of adolescents among parents, researchers, and teachers. ${ }^{23}$

21. G. Stanley Hall, Adolescence, vols. 1 and 2 (Englewood Cliffs, N.J.: Prentice-Hall, 1904).

22. Carol M. Worthman, "Epidemiology of Human Development," in Hormones, Health, and Behavior: A Socio-Ecological and Lifespan Perspective, ed. Catherine Panter-Brick and C.M. Worthman (Cambridge, England: Cambridge University Press, 1999|, 47-104 and Margaret. J. Finders, "Raging Hormones: Stories of Adolescence and Implications for Teacher Preparation," Journal of Adolescent and Adult Literacy 42 (1998/1999): 252-63.

23. Males, Scapegoat Generation. 
FEAR OF YOUTH. This attitude is represented in popular cultural texts that portray youth as problems. Think, for example, of movies such as American Beauty in which three teens engage in various forms of resistance to their parents, or of television shows such as Beverly Hills 90210 , in which the different young people move from one serious problem (such as drug addiction, alcoholism, or anorexia) to another. ${ }^{24}$ Similarly, television commercials and popular music texts portray youth as gangsters, slackers, or pimply faced and confused. Such popular cultural texts tell young people how they are "supposed" to act; in a recent conversation with a group of adults, one mother reported that her teen son expressed some relief when he learned that he did not have to engage in acts of resistance upon "entering adolescence." Powerful messages had communicated to him the need to act like a teenager, even though he did not feel the need to resist the adults around him. These texts also send strong messages to parents, teachers, and other adult community members about what they should fear from young people, so that adults typically talk about adolescents as problems, even as they acknowledge that they really have not experienced real problems with the adolescents in their own lives.

In fact, I have observed this talk about fear of youth as I have interacted with adults about my research with youth. I have studied the literacy practices of adolescents for ten years, and throughout my work with youth, I land many of my colleagues in adolescent and secondary literacy) have been troubled by the marginalization of adolescents' literacy learning as a valid scholarly or practical question. ${ }^{25}$ It was not, however, until I had my own child that I realized how pervasive the dismissal, and even fear, of adolescents is in larger culture. As I spoke with various people about my new daughter, I would often mention that I was looking forward to adolescence because of my lack of aptitude in interacting with young children. My comment was routinely met with looks of disbelief, paternalistic amusement, or downright horror. I often heard, "Just wait until it hits" or similar comments about the horrors of adolescence. I was intrigued by the consistency of these reactions, and what began as an informal observation became a more formalized "test" that I continue to make of people's discourse about youth. As I have surveyed people's perspectives on adolescence, I have found that only one person, among hundreds I have spoken to, considered living and working with adolescents a pleasurable and productive experience.

My observation of people's negative reactions to adolescents is underscored by the way people typically react to the research that I do. Invariably, upon learning that I work with youth, and particularly with gang-connected youth, people ask, "You work with teenagers? With gang kids? How? How do get them to trust you? To talk to you? Is it dangerous?" Each question is spoken with an eye toward my dress, body, and age. Implicit in these consistently asked questions is the assumption that adolescents resist adults, that working with adolescents is difficult, and perhaps even dangerous.

24. American Beauty, Dreamworks Home Entertainment, video, 2000.

25. Moje et al., "Reinventing Adolescent Literacy for New Times," 400-11. 
Some might dismiss these responses as harmless - after all, everyone makes jokes about adolescents. And I would agree that "everyone" does make jokes about the problems of adolescence because, in fact, the popular discourse of adolescence or youth is adolescent-as-raging-hormone, as problem, as out-of-control, as confused, or as resistant to adults. ${ }^{26}$ The problem with the pervasiveness of this discourse is that it gets lived out, with little question, in our teaching, research, and theory. As Margaret Finders argues, a raging hormone perspective is suspiciously pat - it locates the assumed problems of adolescence with something inside the individual that cannot be controlled by teachers or parents. ${ }^{27}$ A raging hormone discourse is also deeply troubling because it plays on and plays into dichotomies between reason and emotion, suggesting that people are either rational, literate beings, or they are adolescents. It is not surprising, given the hormonal perspective, that attention in the literacy field has been diverted from the cognitive, social, and political practices (including literacy and textual practices) of young people. Such a discourse of youth or adolescence as hormonally driven and problematic may also explain why measures designed to prevent youth conflict rarely include an emphasis on what youth are thinking, reading, and writing about, and why, in some cases, schools and other organizations have begun a surveillance of youths's textual practices. ${ }^{28}$ As Mike Males compellingly argues, youth are society's scapegoats, an easy target, and the raging hormone theory provides a convenient explanation..$^{29}$

In an ironic twist, the discourse of youth as problem is exacerbated by the literacy field's failure to analyze carefully how and why youth use and make sense of a wide range of print and mass media texts. This failure allows the field /and educational theory writ largel to accept the raging hormone model of adolescence as an explanation for every youth issue from extreme youth conflict to teen pregnancy. If we looked carefully at all texts available to youth (consider, for example, the conflict represented in Shakespeare's Romeo and Juliet), then we might not be so quick to assume that hormones alone are responsible for how youths resolve conflicts in their everyday lives. If we took seriously the idea that adolescents are sophisticated meaning-makers who use various texts to represent or construct identities and subject positions in the world, then we might not neglect to examine how they make these meanings. We might find that we could learn something important about meaning-making through literacy as well.

My emphasis here on examining the contexts that support problems in youth experience is not meant to suggest that we should not take recent acts of youth

26. Margaret J. Finders, Just Girls: Hidden Literacies and Life in Junior High (New York: Teachers College Press, 1997); Howe and Strauss, Millennials Rising; and Marjorie Mayers, Street Kids and Streetscapes (New York: Peter Lang, 2001).

27. Finders, "Raging Hormones."

28. Collette Daiute, "Narrative Sites for Youths' Construction of Social Consciousness," in Construction Sites: Excavating Class, Race, Gender, and Sexuality among Urban Youth, ed. Michelle Fine and Lois Weis (New York: Teachers College Press, in press) and Calvin Morrill, "Telling Tales in School: Youth Culture and Conflict Narratives," Law and Society Review 34, no. 3 (2000): 561-65.

29. Males, Scapegoat Generation. 
violence seriously. It is important to note, however, that such acts are not new. Urban youth, particularly those living in low-income communities, experience or are engaged in conflict on an almost daily basis, but such incidents rarely get the attention paid to acts of violence by suburban, white, middle-class youth. In addition, I would argue that highly publicized individual cases of extreme violence only serve to underscore the need to examine the contexts of youth experience closely and to question dominant assumptions about raging hormones. If hormones are so out of control in some sort of hopeless physiological phase of development, then would not all adolescents be engaged in such conflicts? Furthermore, the raging hormones model is challenged by my data from working with youth affiliated with street gangs. For example, when I asked one young man why he affiliated with gangs, he looked me in the eye and succinctly responded, "Everything's a gang." A young person who can make such a statement - and go on to compare gang practices to a number of world conflicts in which the United States was actively involved - does not appear to be living at the whim of raging hormones. He is, I would argue, reasoning about the role of sanctioned and unsanctioned violence in human interaction. He is thoughtful and sure about the contexts that support, if not promote, his gang practices.

\section{More than Raging Hormones: Alternative Perspectives on Adolescence}

Peter Mosenthal moves beyond the raging hormone model by arguing that adolescence is a relatively new stage in human development. ${ }^{30}$ Adolescence, he argues, was spurred by industrialization and the concomitant need to prepare children via schooling for a particular kind of workplace. In other words, adolescence, according to such perspectives, is a socially and politically constructed phenomenon, one that by virtue of its social, political, and historical situatedness needs to be understood as a changing phenomenon. Even such theories of adolescence as a socially constructed phase tend, however, to emphasize it as a time of "becoming," a time that is fraught with problems for youth. ${ }^{31}$

Adolescence as BeCOMing. The problems for adolescents, according to these perspectives, stem from the tensions and dilemmas youth experience as they sample from multiple experiences, in multiple social groups, while "becoming" adults. This perspective has utility for thinking about the literacy practices of people in this age group because youth do, indeed, experience many different contexts and practices. In fact, one wonders why more focus is not put on how youth use texts and literacies as part of that becoming process. Both the emphasis on problems of adolescence and on adolescence as a phase may suggest an answer. Because adolescents are considered to be struggling through a phase of life filled with problems, tensions, and dilemmas, their literacy practices - even when acknowledged as worthy of study - are often

30. Peter B. Mosenthal, "Reframing the Problems of Adolescence and Adolescent Literacy: A DilemmaManagement Perspective," in Alvermann et al., Reconceptualizing the Literacies in Adolescents' Lives, 325-52. See also Comaroff and Comaroff, "Millennial Capitalism" and J.E. Kett, Rites of Passage: Adolescence in America, 1790 to the Present (New York: Basic Books, 1977).

31. Lorri Neilsen, "Playing for Real: Performative Texts and Adolescent Identities," in Alvermann et al., Reconceptualizing the Literacies in Adolescents' Lives, 3-26. 
reduced to artifacts of adolescent confusion, rather than as tools for meaningmaking, boundary crossing, and agency. ${ }^{32}$ The analyses of adolescent literacies in problem-based studies typically revolve around how youth use literacy to resolve problems or, as Mosenthal argues, how literacy could be used to manage dilemmas of adolescence and beyond..$^{33}$ Such studies make important contributions to literacy research because they illustrate how adolescents navigate different contexts, but they do not necessarily reveal the potential of youth literacy practices.

A number of educational psychologists have taken adolescent development especially in the middle years of adolescence - quite seriously. Jacquelyn Eccles and her colleagues, for example, have illustrated repeatedly that the contexts of secondary schooling represent a developmental mismatch for adolescents because at the very time they need to practice being independent, adults around them/especially in school) seek more than ever to control their movements, thoughts, and interactions. $^{34}$ Thomas Cottle argues that we need to attend to how popular culture makes multiple and often conflicting demands on the fields of attention that shape adolescent "minds." ${ }^{35}$ And a small number of adolescent literacy scholars have contributed rich portraits of youths' learning literacy in secondary school content areas. ${ }^{36}$ Youth cultural scholars have documented youths' social and literate practices (several such studies are discussed in the following section).

In short, we do not lack a research base on adolescent development, secondary school literacy learning, youth literacy, and youth culture, but we do lack attention to the literacies of youth on a broader scale. The three books reviewed here, books that each purport to present fundamental issues in literacy, do not attend to youth literacies. Moreover, few federally funded initiatives and federally or locally mandated policies are aimed at youth studies. Even fewer initiatives or policies are focused on youth literacy studies. Instead, federal and state funding and policy

32. Neilsen, "Playing for Real," 1998 and Finders, Just Girls.

33. Mosenthal, "Reframing the Problems of Adolescence."

34. Jacquelyn. S. Eccles, Sarah Lord, and Carol Midgley, "What Are We Doing to Early Adolescents? The Impact of Educational Contexts on Early Adolescents," American Journal of Education 99 (1991): 521-42 and Jacquelyn. S. Eccles et al., "Negative Effects of Traditional Middle Schools on Students' Motivation," Elementary School Journal 93 (1993): 553-74.

35. Thomas J. Cottle, Mind Fields: Adolescent Consciousness in a Culture of Distraction (New York: Peter Lang, 2001).

36. See, for example, Donna E. Alvermann, "Peer-Led Discussions: Whose Interests Are Served?" Journal of Adolescent and Adult Literacy 39 (1995/1996): 282-89; Donna E. Alvermann, Jennifer Moon, and Margaret Hagood, Popular Culture in the Classroom: Teaching and Researching Critical Media Literacy (Newark, Del.: International Reading Association/National ReadingConference, 1999); Steven Z. Athanases, "Diverse Leamers, Diverse Texts: Exploring Identity and Difference Through Literacy Encounters," Journal of Literacy Research 30, no. 2 (1998): 273-96; Deborah R. Dillon and Elizabeth B. Moje. "Listening to the Talk of Adolescent Girls: Lessons About Literacy, School, and Lives," in Alvermann et al, Reconceptualizing the Literacies in Adolescents' Lives, 193-224; Kathleen A. Hinchman and Patricia Zalewski. "Reading for Success in a Tenth-Grade Global-Studies Class: A Qualitative Study," Journal of Literacy Reseorch 28 (1996): 91-106; David G. O'Brien, "Multiple Literacies in a High School Program for 'at-Risk' Adolescents," in Alvermann et al., Reconceptualizing the Literacies in Adolescents' Lives, 27-49; and LeeAnn M. Sutherland, "African American Girls' Experiences with Classroom Texts and Literacy Practices: A Study of Literacy, Identity, and Multicultural Education"; Ph.D. Dissertation, University of Michigan, in press. 
decisions are repeatedly directed at the literacy learning of young children. Why? Perhaps because adolescents are typically considered to be little more than a bunch of raging hormones. Perhaps because adolescents are seen as people moving through a phase. Perhaps because adolescents are seen as problems to be avoided.

Youth Culture. To take seriously what youth can teach the field about literacy processes, practices, and identity construction, we need to develop theories that make spaces for youth literacies as powerful and productive tools, and that allow the field to trace how the problematic and violent practices that youth do engage in are often a function of the social, political, and very adult contexts in which they live, work, and learn. Youth cultural studies offer such perspectives. Youth cultural studies do not deny that young people are engaged in identity representation and development at some level, but such studies typically do not emphasize "becoming," with a sense of some final, stable end product or identity. Nor do they assume that youths are struggling with problems any more than are children or adults. Instead, youth culture studies focus on how youth construct and represent themselves in hybrid ways across different spaces and contexts, and often show how youth conflict or problems are a function of social and political (and adult) contexts. Dwight Conquergood, for example, illustrates that the discourse of loyalty in street gangs parallels the discourse of nationalism and patriotism, and he argues that it is not surprising that youth engage in gang practices, given the national and political contexts in which they are immersed..$^{37}$

Several youth cultural studies examine youth' ${ }^{\prime}$ experience from the perspective of youths, making spaces for youth to tell their own stories, rather than to report stories layered with adult, often white, mainstream assumptions about what it means to be a youth. For example, in contrast to the perspective that assumes youth are either naturally violent (all those hormones) or react in violent ways to the tensions of becoming in adolescence, Calvin Morrill presents narrative analyses that demonstrate youths' purposeful reasoning behind the conflicts in which they are engaged. ${ }^{38}$ Arguing for an "elusive" perspective on youth culture, Daniel Yon traces the different roots and routes of youth identities, illustrating that youth represent many different identities simultaneously, with little confusion or frustration. ${ }^{39}$ Similarly, Ann Locke Davidson presents six case studies of youth "making and molding identity" around differences in race, gender, and how they engage academically in school.$^{40}$ Davidson illustrates the ways that youths' participation in everyday practices both reproduce and contest larger social forces of economic and social

37. Dwight Conquergood, "For the Nation! How Street Gangs Problematize Patriotism," in After Postmodernism: Reconstructing Ideology Critique, ed. Herbert W. Simons and Michael Billing (Newbury Park, Calif: Sage, 1994), 201-21.

38. Morrill, "Telling Tales in School."

39. Daniel Yon, Elusive Culture: Schooling, Race, and Identity in Global Times (Albany: State University of New York Press, 2000\}.

40. Ann Locke Davidson, Making and Molding Identity in Schools: Student Narratives on Race, Gender, and Academic Engagement (Albany: State University of New York Press, 1996). 
oppression and in how students make and remake themselves on an almost daily basis.

Literacy and Youth Culture. Youth cultural work in literacy focuses on how youth use literacy and text to navigate, synthesize, and hybridize multiple spaces. These studies also emphasize how literate practice gets complicated and changed by the social and political practices demanded in a globalized, technologized, and hybridized world. ${ }^{41}$ Such work resists reducing youths' uses of literacy to either resistant or deviant acts. My own work, for example, demonstrates that even young people most likely to be engaged in violent practices - gang-connected youth - are actively using texts and literacy practices to make sense of their everyday lives. In fact, their gang-connected literacies, often seen either as deviant (in that case usually not even considered literacy) or resistant, were more often than not simply ways of identifying with other youth, getting through the day, or finding a space to belong. ${ }^{42}$ Similarly, Miriam Camitta has illustrated how urban adolescents use "vernacular" literacies in and out of school to "take hold" of their lives, to write themselves into the world, and Margaret Hagood presents a case study of one young man to show how his uses of text served to resist subject positions and identities that others constructed for him. ${ }^{43}$

James Gee offers an interesting possibility for thinking about the power and importance of youth literacy practices when he talks about youths as "shape-shifting portfolio people. ${ }^{\prime 44}$ For Gee, shape-shifting portfolio people actively construct their identities in relation to the multitude of discourses and cultural models available them via new texts and new experiences in an information-based, globalized, fast capitalist economy. The sense of shape-shifting youth is distinctly different from youth who are at the whim of hormones or who are struggling through the problems of deciding who to become. The youth of Gee's cases are people who make decisions and create both hybrid and fluid identities that work across and within multiple spaces, times, and places. Expanding on this perspective, Josephine Young, Deborah Dillon, and I contrast the literacy practices and uses of texts of three youth from different locations, socioeconomic positions, and ethnic backgrounds to illustrate how these youth strategically and tactically construct identities, or "portfolios," that help to achieve particular life goals. ${ }^{45}$

41. Alvermann et al., Reconceptualizing the Literacies in Adolescents' Lives; Michele Knobel, Everyday Literacies (New York: Lang, 1999); and Cynthia Lewis and Bettina Fabos, "Chatting on-Line: Uses of Instant Message Communication among Adolescent Girls"; paper presented at the National Reading Conference, Orlando, December 1999.

42. Moje, "Reinventing Adolescent Literacy for New Times."

43. Miriam Camitta, "Vernacular Writing: Varieties of Literacy among Philadelphia High School Students," in Cross-Cultural Approaches to Literacy, ed. Brian V. Street (Cambridge, U.K.: Cambridge University Press, 1993|, 228-46 and Margaret Hagood, "Critical Literacy for Whom?" Reading Research and Instruction (in press).

44. Gee, "Millennials and Bobos."

45. Josephine Peyton Young, Deborah Dillon, and Elizabeth Birr Moje, "Shape-Shifting Portfolios: Millennial Youth, Literacies, and the Game of Life, "in New Literacies and Digital Technologies: A Focus on Adolescent Learners, ed. Donna E. Alvermann (New York: Peter Lang, in press). 
In short, each of these studies challenges the notion that young people simply respond to the conditions around them by resisting or accommodating experiences. ${ }^{46}$ Like all people, young people use popular cultural texts and experiences in unpredictable ways to make sense of and take power in their worlds. ${ }^{47}$ What is more, close-up studies of youth often show youth to be making productive uses of literacy, to be sophisticated users of print and other forms, and even to be kind and generous people who are concerned about making a difference in the world. Following such models, the questions relevant to literacy and educational theory become what role literacy plays in adolescent shape-shifting or identity construction, and what we can learn about both literacy and youth if we attend to these hybrid, shape-shifting practices. Furthermore, how do new literacies and types of texts get invented as youths engage in shape-shifting? What are the implications for children's and adults' literacy learning?

It should be clear from this brief overview of research and theorizing on adolescent and youth literacy that a fair amount of work has been done in recent years on the topic. However, only two of the studies or commentaries presented across the three texts under consideration in this essay allude to the idea that the power of literacy may lie in the act of engaging in literacy and in shaping identities, rather than in some concrete economic, social, or political gain. Shirley Brice Heath's chapter, "Literacy and Social Practice," and Amy Shuman and Bennis Blue's chapter, "The Ethnography of Writing" in the Handbook both speak to the importance of studying the everyday experience of people and, in Heath's words, of "increased attention to ways that time, space, and role expand reading and writing in layered and innovative interactions for play and performance, work and leisure." 48

In contrast to these commentaries, Powell suggests that unless youth especially marginalized youth - are offered critical literacy pedagogies in school, they will not learn to critique language and texts and they will, ultimately, be silenced, their identities crushed. She offers, for example, the case of university students who wrote a protest letter in African American vernacular English to decry the killing of a classmate's brother and found their words rejected when multiple media sources refused to publish their letter. Powell's concern over the silencing of different languages and discourses is valid, but how are we to know what sense these young adults made of the experience? Should we assume that the media's rejection of their text made the practice less powerful for them? Homi Bhabha argues, in fact, that oppositional narratives arise when people struggle against oppression and

46. J. Fiske, Understanding Popular Culture (London: Routledge, 1989) and Lawrence Grossberg, "Cultural Studies: What's in a Name? (One More Time)," Taboo: The Journal of Culture and Education 1 (1995): 1 37.

47. See Donna E. Alvermann, "Reading Adolescents' Reading Identities: Looking Back to See Ahead," Journal of Adolescent and Adult Literacy (in press); Camitta, "Vernacular Writing"; Lewis and Fabos, "Chatting on-Line"; Amy Shuman, Storytelling Rights: The Uses of Oral and Written Texts by Urban Adolescents /Cambridge: Cambridge University Press, 1986).

48. Shirley Brice Heath, "Literacy and Social Practice," in Literacy: An International Handbook, ed. Daniel A. Wagner, Richard L. Venezky, and Brian V. Street (Boulder, Colo.: Westview Press, 1999), 102-6. 
dominance ${ }^{49}$ Could this literate practice have served to deepen the youths' understanding of critique and to challenge their commitment to collective struggle? How might the practices -- the translation of discourses, the writing itself, and the analyzing of the rejections they experienced - be tools for developing new understandings of the world and new literacy practices to challenge the world?

Youth offer a unique possibility for studying the power of literacy. Whether or not one agrees with the concept of "becoming," youth are popularly construed as being between many spaces: childhood and adulthood; work and play; home, school, peer group, and community; romance and sex; popular culture and academic culture; science class, history class, and English class; comic book and Internet; local community and global marketplace. The list of in-betweens goes on and on. Youth, by virtue of their age and their new experiences that come with that age, are in the position to make a number of interesting choices among texts, experiences, and practices. In fact, these experiences are often offered to youth in an unstructured, unmonitored, and unsystematic fashion. Consider, for example, the typical secondary school, which despite its emphasis on controlling students' behaviors, offers one class after another with little, if any, connection made to the classes offered before or after. Consider the types of employment youth often have access to, which are typically after-school or weekend jobs that make use of their physical labor, but rarely offer them systematic training in particular skills. Consider the unmonitored after-school activities of many youth, which may include watching television; listening to music; surfing the Internet; or kicking it with friends on the street, at the mall, or in a community center. Even community-based organizations with specific after-school programs offer a palette of activities for youth. Youth, then, have a particular burden of navigating and negotiating a number of different, and often disconnected, experiences. This burden may, however, empower youth to learn navigation skills that younger and older people do not require.

Youth in the millennial world of high-speed information transfer lie in the inbetween of global and local spaces. ${ }^{50}$ They have access to enormous amounts of virtually unedited information, from all over the world. And their access is not only to information, but also to new formats for receiving and constructing information. It is in the in-between that new forms of cultural production - new texts and new literacies - emerge. Through studies of adolescents using literacy, the link between literate practice and identity construction and representation is revealed, in part because adolescents are in-between multiple spaces, and in part because, as Cottle argues, adolescents can be more metacognitive about their practices than can children. ${ }^{51}$ Youths use texts and particular literacy processes in ways that position them as powerful in certain spaces or that allow them to claim membership in certain

49. Homi Bhabha, "Looking Global"; paper presented at the Globalism in its Place, University of Michigan, Ann Arbor, March 2001. See also Michel Foucault, Discipline and Punish: The Birth of a Prison (New York: Vintage, 1977).

50. Bhabha, "Looking Global."

51. Cottle, 2001 . 
groups. ${ }^{52}$ These young people move throughout any number of seemingly contradictory practices in a single day, bringing to and taking away from those practices various literacy practices and various texts. Homi Bhabha argues that we should study these in-between spaces to understand more about how people make identities. ${ }^{53} \mathrm{I}$ believe that we need to study literacy practices in these in-between spaces in the lives of youth to understand more about conventional literacy processes and about how new literacies are invented and transformed in hybrid spaces. Studying youth culture and literacy practices can reveal the sophisticated purposes for literacy that all people bring to literacy practice, purposes that can be incorporated into the teaching of multiliteracies. ${ }^{54}$

The need to study how youth engage in sophisticated practices to navigate multiple spaces is especially important in light of studies that position youth as struggling to use print texts in meaningful ways. As previously discussed, Guthrie and Metsala, in their chapter on literacy in North America, present data from the NAEP to illustrate that there is some question as to whether youth can integrate information across multiple texts, relate textual meanings to personal experience, and compose complete messages in the form of stories and reports for actual audiences $(L I H, 382)$. In my own research, however, I have observed youth engaging in those very skills, albeit not with traditional academic or school-sanctioned texts. The standardized assessments that literacy researchers, teachers, and policymakers use to evaluate youths' literacy proficiences are not likely to demonstrate whether youth can engage in these skills on everyday tasks. Consequently, youth literacy research that looks beyond broad-based and standardized assessment scores needs to be included in the portrait of what young people can do and are doing with literacy in the world.

Moreover, even among existing studies of adolescent/secondary literacy or among cultural studies of youth there is little research that demonstrates proficiency among youth on Guthrie and Metsala's fourth dimension of high reading achievement: the ability to use text knowledge, or even personal experience, to evaluate science observations or historical documents $(L I H, 382) .{ }^{55}$ Are youth not engaging in these practices, or are youth literacy studies not examining these practices and skills? Initial data analyses in my own current work suggest that youths draw from popular cultural texts not only to evaluate, but also to construct scientific and historical knowledge. The questions then arise how are popular cultural texts such as the movie, Erin Brockovich, merging with and reshaping texts written by scientists, news media, community action groups, and legal groups? ${ }^{56}$ What are the

52. Scott F. Oates, "Literacy as Everyday Practice: A Cross-Case Analysis of Three Sites of Learning" (doctoral dissertation, University of Utah, 1998).

53. Bhabha, 2001; see also, Homi K. Bhabha, The Location of Culture (New York: Routledge, 1994).

54. New London Group, "A Pedagogy of Multiliteracies: Designing Social Futures," Harvard Educational Review 66 (1996): 60-92.

55. See also Gee's discussion of shape-shifting portfolio people who use literacy not only to get and synthesize information, but also to make themselves into different people, Gee, 2001.

56. Erin Brockovich, directed by Steven Soderbergh, written by Suzanna Grant, Columbia Pictures and Universal Pictures, Culver City, Calif., film, 2000. 
implications of these mergings? Are hybrids of popular cultural, community knowledge, and academic knowledge valuable? Or do they produce inaccurate and inadequate understandings of science, history, and other disciplines? What impact do youths' mergings of knowledges have on their school success? More research in this area is needed to address these important questions and to advance youth literacy theory and content area learning for all age groups.

In sum, despite a rich base of research in youth cultural studies, and a growing base in youth literacy studies, we need to know more about the new literacies that youth use. In particular, we need to obtain a better understanding of how youth navigate complex academic texts, both to complicate the current image of youth as struggling readers of sophisticated texts and to inform our thinking about how better to teach children, youth, and adults how to make meaning from complex texts. And, if we acknowledge that all youth's literacy practices can be considered tools for making meaning, then we need to ask what are the particular cognitive consequences of the particular literacy and textual tools privileged by adolescents, such as popular cultural texts, electronic technologies, and unsanctioned peer groups and practices. What are the social, political, and economic consequences of these texts and experiences? What can these consequences - and an in-depth study of how youth enact these literacies across global and local spaces, times, and places - teach us about children's and adult's literacy learning?

\section{Conclusions ANd Beginnings}

Why study youth culture and youth literacies? Put simply, the answer could be, "Because they exist." Put more complexly, to fail to study youth literacies is to support narrow conceptions of what it means to learn and use literacy. The lack of focused attention to the literacies of youth in these three texts and in educational policy and theory writ large reveals something about the dominant assumptions in the field, regardless of currently popular conceptions of literacy that many scholars espouse. That is, despite arguments about the complex nature of literacy that abound in the field - and despite calls for "broadened" conceptions of literacy - the neglect of youth literacies makes clear that literacy as a construct remains rooted in narrow conceptions of schooled, basic literacy processes which assume that literacy learning ends in childhood. The focus on adult literacy campaigns and research around basic processes in adult literacy across these texts and in the field at large is based on the assumption that the adults who need literacy education need it because they failed to learn literacy in childhood.

Even a stance that assumes that literacy learning is centered in childhood and remediated in adulthood, however, raises the question of why we continue to neglect the literacy development of adolescents. A conception of literacy that assumes literacy learning ends in childhood would suggest a need to attend to the children who do not learn basic print literacy by the time they move into adolescence. And yet, little funding is designated even for the study of so-called struggling readers lalthough it is worth noting that the notion of "struggling adolescent readers" is one of the few areas of adolescent literacy that has drawn any national or state policy 
attention). By and large, the field continues to focus on early childhood or adult literacy, allowing the span of years between childhood and adulthood to remain an unattended void. Such an oversight allows society to neglect and, in some cases, to devalue, youth.

My remarks should not be read as a critique of any one of the three texts as an individual work. These texts offer useful summaries of literacy theory and research on children and adults. Rather, I read these three books together as a representation of key issues in the field, and I left my reading dismayed, not because the books are of poor quality, but because of what is left unsaid across the books about a large segment of the world's population. Literacy theorists and educators have much to learn about how to support the academic and social literacy learning of young people, especially within the contexts of large, impersonal, and of ten fragmented secondary schools. The literacy field is missing a prime opportunity to learn not only about youth literacy but also from youth as they teach us about how complex literacy processes and practices develop and change in multiple contexts, times, and spaces. Until we include youth in literacy theory and policy, we will continue to develop theories of literacy learning, development, and practice that focus primarily on children and adults, and we will overlook a group of people who have much to offer educational theory and the world. 